\title{
Acute Appendicitis Due To Enterobius Vermicularis in a Middle Aged Adult, Rare Finding- A Case Report.
}

\author{
Dr. Ujwal Kumar ${ }^{1}$, Prof.N.K.Jha ${ }^{2}$, Dr.D.K.Sinha ${ }^{3}$ \\ ${ }^{1}$ (Junior resident, Department of Surgery, R.I.M.S, Ranchi, India) \\ ${ }^{2}$ (Head of Department, Department of Surgery, R.I.M.S, Ranchi, India) \\ ${ }_{3}^{3}$ Department of Surgery, R.I.M.S, Ranchi, India)
}

\begin{abstract}
The finding of E. vermicularis in appendectomy pathological specimens is infrequent. We report a case of acute appendicitis due Enterobius vermicularis in a middle aged adult. Acute appendicitis due to parasitic infection is rare. Clinical features of intestinal Enterobius infection can resemble acute appendicitis, though the patient might not have appendicitis. If E. vermicularis is found to be the cause of appendicitis on histopathological examination of the excised appendix though rare as in our case, the patient should be given anti helminthic post operatively.
\end{abstract}

Key words: Appendicitis, Enterobius vermicularis, helminth, intestinal, parasitic infection.

\section{Introduction}

Infection due to Enterobius vermicularis is almost the commonest helminth infection worldwide [1] . Pinworm infestation is usually asymptomatic. The reported incidence of Enterobius infestation in patients with symptoms of appendicitis ranges from $0.2-41.8 \%$ [2] . Several studies tried to document the relationship of pin worms and appendicitis but their causal relationship remains controversial . Enterobius vermicularis infestation can have a varied presentation.. Non specific symptoms of perianal pruritis, decreased appetite, loss of sleep may be seen in children . E. vermicularis in the appendix can produce symptoms of acute appendicitis or 'appendiceal colic', independent of histological acute inflammation, or can produce no tissue reaction or a chronic inflammatory infiltrate of eosinophils may be associated or it can be responsible for histological appendicitis in extremely rare circumstances as is in our case.

\section{Case Summary}

A 27 year old male patient presented to us with the complaints of colicky pain in the right lower abdomen for 2 days associated with vomiting ( 2 episodes) and fever for 1day. On examination patient was febrile and dehydrated. On abdominal examination, there was tenderness and guarding in the right iliac fossa. There was no palpable lump and no signs of generalized peritonitis. A clinical diagnosis of acute appendicitis was made. Blood investigations revealed leucocytosis along with neutrophilia. After fluid resuscitation and administration of broad spectrum antibiotics, an open appendectomy was performed. Appendix was found inflamed. It was sent for histopathological examination, which revealed acute appendicitis showing cut section of a parasite: Enterobius vermicularis ( Fig. 1 and Fig. 2). The patient was given 2 doses of Mebendazole post operatively and follow up till date is uneventful.

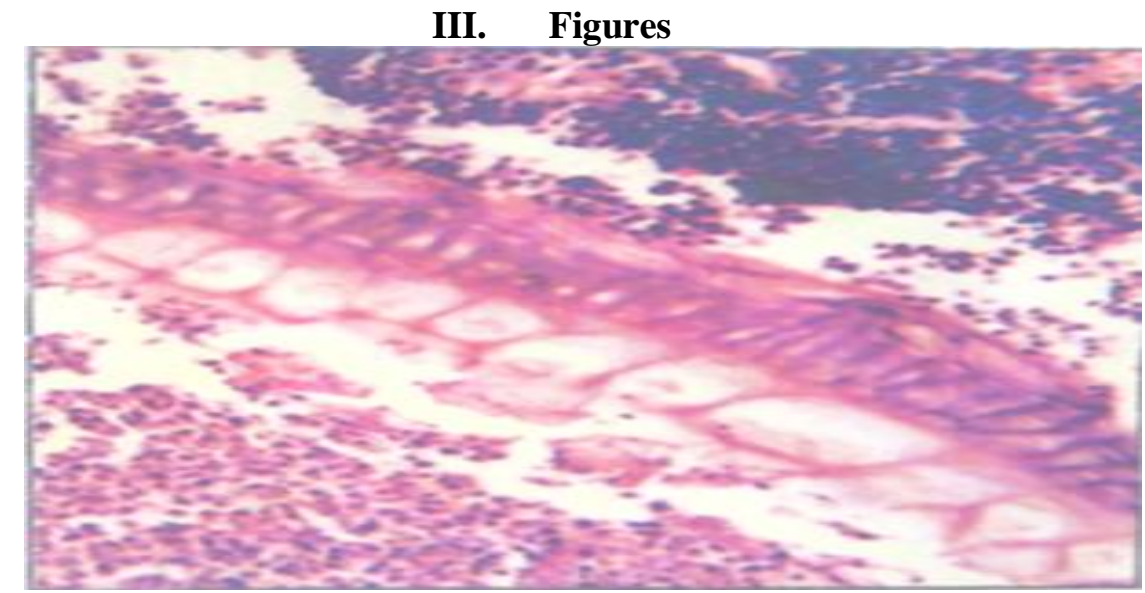

Figure 1 : Histopathological slide showing acute appendicitis. 


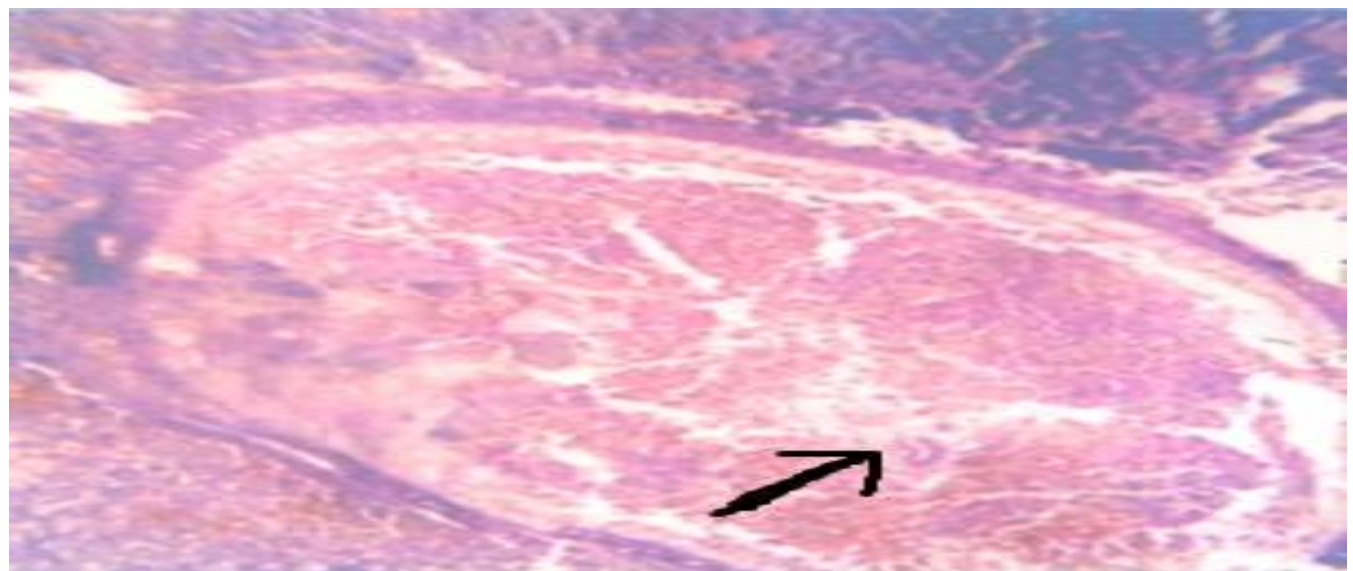

Figure 2 : Cut section of appendix showing Enterobius vermicularis

\section{Discussion}

Out of 178 specimens biopsied over a period of 2 years, only one specimen of the above described patient showed Enterobius vermicularis as the cause of appendicitis. Parasitic infections rarely cause acute appendicitis, especially in adults. A careful evaluation of the non specific symptoms described along with eosinophilia on laboratory examination, could prevent unnecessary appendectomies . The configuration of appendix with a narrow lumen and long length predisposes to closed-loop obstruction. Obstruction of the appendiceal lumen by worm, as in our case, contributes to bacterial overgrowth and continued secretion of mucus, leading to intraluminal distention and increase in pressure $[3,4]$. This leads to an impaired lymphatic and venous drainage resulting in mucosal ischemia. These findings in combination promote a localized inflammation . Inflammation of the adjacent peritoneum gives rise to localized pain in the right lower quadrant . Acute appendicitis warrants an appendectomy. The patient needs an anti helminthic if worms are the cause of appendicitis for deworming and to avoid other symptoms of worm infestation. Careful history, clinical examination and look out for pruritus ani or eosinophilia in the blood examination, will definitely prevent unnecessary appendectomies [5].

\section{Conclusion}

Acute appendicitis due to Enterobius vermicularis, though a rare entity, should be borne in mind and therefore all appendectomy specimens should be subjected to histopathological examination to avoid missing the diagnosis and the patients should be treated accordingly using antihelminthics post operatively.

\section{Journal Papers:}

\section{References}

[1] Aydin O. Incidental parasitic infestations in surgically removed appendices: a retrospective analysis. Diagnostic Pathology 2007;2:16.( PubMed)

[2] Eleni Efraimidou, Anthia Gatopoulou, Charilaos Stamos,Nikolaos Lirantzopoulos and George Kouklakis; Enterobius Vermicularis infection of the appendix as a cause of acute appendicitis in a Greek adolescent: a case report, Cases Journal 2008, 1:376 doi:10.1186/1757-1626-1-376 (Cases Journal).

\section{Chapters in Books:}

[3] John Maa, Kimberly S.Kirkwood; The Appendix; Sabiston Textbook of Surgery18 th Edition,2009,2, 49 (1334).

[4] P Ronan, O Conell; The vermiform appendix; Bailey and Love's Short textbook of Surgery, 25 th edition2008, 67(1206).

\section{Journal Papers:}

[5] Stavros Panidis, Daniel Paramythiotis, Dimitris Panagiotou, Georgios Batsis,Spyridon Salonikidis, Vassiliki Kaloutsi and Antonios Michalopoulos; Acute appendicitis secondary to Enterobius vermicularis infection in a middle-aged man: a case report,Journal of medical case reports. 2011, 5:559.( Journal of medical case report). 